\title{
Preparedness to Flood Disaster amongst Households in Eastern Malaysia
}

\author{
Fakhru'l-Razi Ahmadun, Aini Mat Said and Ahmad Azan Ridzuan
}

\begin{abstract}
Monsoonal floods are annual occurrences which varies in terms of severity, place and time of occurrences. The objectives of this study were to explore factors influencing preparedness to flood disaster among households residing in flood risk area in the city of Kuching, Sarawak, East Malaysia. A total of 200 respondents were survey using a questionnaire. Findings indicated critical awareness, attitude, subjective norm, risk perception, trust in agencies and intention to prepare for flood disaster was of moderate level. Although the respondents lived in flood prone area, $38 \%$ of them had low level of preparedness. Three variables namely risk perception, trust in agencies and sense of community explained 57.3 percent of the variance in intention to prepare and the strongest predictor was trust in agencies. An appropriate disaster education the could be designed by incorporating the findings so as to enhanced flood disaster preparedness among the community.
\end{abstract}

Keywords — flood, disaster, preparedness, community.

\section{INTRODUCTION}

Malaysia comprises of eleven states in Peninsular West Malaysia, Kuching is the capital of Sarawak which is one of the states in Eastern Malaysia. About 10\% of the country's landmass is flood risk area and affecting 5.7 million of the population (18\%) from a total population of 31.8 million [1]. The country is susceptible to three types of floods such as flash floods, monsoon floods and flood caused by high tides. On average, there are 117 flood occurrences per year. Malaysia faces two monsoon winds seasons, the Southwest Monsoon from April to September, and the Northeast Monsoon from October to March. The Northeast Monsoon brings in more rainfall compared to the Southwest Monsoon and this usually leads to serious flooding annually. These floods are extensive and resulted in significant loss of lives, damage to properties, crops, livestock and public infrastructure. Many population in the low lying areas have to be evacuated, schools closed, roads cut off and closure of some airports.

Despite of experiencing flood occurrences annually, there seems to surface many problems responding to them particularly when the magnitude of the disaster is big. For

Fakhru'l-Razi Ahmadun is the Director of Humanitarian Assistance and Disaster Relief Research Centre, National Defence University of Malaysia, Kem Sungai Besi, 5700 Kuala Lumpur, Malaysia..

Aini Mat Said Humanitarian Assistance and Disaster Relief Research Centre, National Defence University of Malaysia, Kem Sungai Besi, and 5700 Kuala Lumpur, Malaysia.

Ahmad Azan Ridzuan, Faculty of Management and Defence Studies, National Defence University of Malaysia, Kem Sungai Besi, 5700 Kuala Lumpur, Malaysia. . example, the December 2014/Jan 2015 flood which had affected five states and 232,913 households were evacuated to 1335 evacuation centers. It resulted in 25 deaths, 8774 houses damaged and estimated RM2.9 billion (USD0.86) of damages to infrastructure [2]. There were many weaknesses with regards to disaster response and relief: evacuation of the victims; evacuation shelters; inter agency co-ordination and communication; relief aids; and logistics. Some of them were highlighted in the ensuing National flood disaster management Conference 2015 which was held in Kota Bharu Kelantan from 14-16 February. A total of 500 experts and practitioners from local universities, ministries and relevant agencies, and other public and private sector stakeholders, including flood victims themselves participated in the conference. A total of 228 recommendations were made under the five pillars of disaster management namely: prevention (46); preparedness (47); response (21); recovery (56) and governance (58) [3]. Consequent to the disaster, National Disaster Management Agency (NADMA) was established under the Prime Minister's Department taking over the responsibility from the National Security Council on 1 October 2015 with the consolidation of the Disaster Management Division of the National Security Council, Post-Flood Recovery Unit of the Prime Minister's Department and the Special Malaysia Disaster Assistance and Rescue Agency (SMART).A special research grant of RM 20 million was offered by the Ministry of Higher Education to higher institutions of learning in the country to conduct a comprehensive study in flood mitigation, preparedness, response and recovery for Malaysia[4] .

The frequency of flood disasters worldwide is increasing and the same scenario is reflected in Malaysia. Peninsular Malaysia coastline is projected to rise with a mean in the range $0.066 \mathrm{~m}$ to $0.141 \mathrm{~m}$ in 2040 and Sabah-Sarawak coastlines is projected to rise with a mean in the range $0.115 \mathrm{~m}$ to $0.291 \mathrm{~m}$ in 2040 [5] and this means that flood magnitude will be worse in the future and impacted greater number of population. It is therefore crucial to build a flood resilient community so as to minimize the social, psychological, economic losses and loss of lives of the people. This research therefore aims to explore the factors that influence preparedness among households residing in flood risk areas.

\section{LITERATURE REVIEW}

Personal preparedness can be describe as behaviours that involve both planning activities and adaptive response, representing a course of self-protective behaviours that could 
reduce loss of life, property or personal injury during disaster [6]. It is imperative that those who are facing the emergency take the initial step to avert the consequences of the hazard. Different types of disaster require slightly different reactions to the early warning, immediate responses, evacuation to safe zones, route to safe zones and termination of the disaster.

Previous studies [7], [8] have shown that residents living in area exposed to hazard are aware of the risk but remain unprepared and continue to do so even though countless effort have been made. In the last decades, several studies have investigated preparedness for natural disasters and the factors that promote the adoption of protective measures among people who live in high-risk zones, even though these studies have mainly focused on seismic risks [9]. Most research suggest that preparedness for a natural disaster is associated with a wide range of factors ranging from personal ( risk perception, attitude, awareness, knowledge) to community related factors such as trust in agencies, subjective norm and sense of community.

Intention to prepare has been found to be significant predictor to preparedness in tsunami, flood, bushfire and volcanic disaster [8]. Reference [10] found that sense of community to be the most influential factor followed by subjective norm, trust, positive outcome expectancy and risk perception, explaining the 57\% variance in intention to prepare for tsunami disaster. A study to gain insight on the community flood preparedness found that both affective and cognitive process influence citizen behavioural intentions [11]. Affective factor such as sense of community which is associated with sense of belonging, security and social responsibility was found to predict intention to prepare for disaster in some communities [12]. As in [13]. The evidence indicated that factors influencing preparedness, attitudes, and behaviors are complex and multifaceted (including demographic characteristics, trust in government efforts, previous exposure to a disaster, and number of dependents in a household) and varying across population groups, households, and individuals, and types of disaster.

Regardless of the inconclusive findings on factors influencing intention to prepare and preparedness to disaster, understanding of those factors through empirical study for a specific community is pertinent. An appropriate disaster education could be designed by incorporating the findings so as to enhance flood disaster preparedness among the community. This research was thus undertaken to gauge the level of preparedness of the households to flood disaster and to ascertain the level and influence of critical awareness, attitude, subjective norm, risk perception trust in agencies and sense of community to intention to prepare and preparedness to flood disaster.

\section{Methodology}

\section{A. Population and Sampling}

In order to represent the Eastern Malaysia, it is either the state of Sarawak or Sabah. Flood evacuees for five year span from 2012 to 2017 showed that Sarawak had a higher number of evacuees. Amongst the regions in Kuching, which is the capital of Sarawak had the highest number evacuees as compared to other regions. The population of the study was the community residing in flood risk areas and had previously been evacuated due to flood. Identification of affected villages was obtained from the Kuching District Office. The head of each selected village assisted in identifying the relevant households. A total of 181 respondents were then selected from five villages in the district. Each household is either represented by the head of the household or the spouse.

\section{B. Instrument Development}

Self-administered questionnaire was used as the instrumentation. The instrumentation comprised of nine sections starting with demographic background followed by critical awareness, outcome expectancy, subjective norm, risk perception, trust in agencies, intention to prepare for flood, sense of community and flood preparedness. The first section consist of demographic variables including gender, age, ethnicity, education level, income, occupation

Flood preparedness was measured using a checklist of safety actions that has been taken to mitigate the impact of flood. The construct consisted of 23 items adopted from Frandsen [14]. Respondents were asked to answer with a 'yes' or 'no' if they has taken any actions in the construct.

This section measures attitude to quantify their belief toward flood preparedness adopted from McIvor and Paton [15]. The construct consists of eight statements that describe the cognitive beliefs or action adopting protective measure preparing for a flood hazard is effective and seen to be too constructive. All items were measured using a 5-point Likert scale ranging from 1 (strongly disagree) to 5 (strongly agree).

The scale to measure subjective norm adopted from [15] used as the foundation to quantify external influence to be viewed from the perspective of four categories which are family, friends, colleagues and community. In total sixteen items were used to measure subjective norm. The respondents were asked to rate the statements they believe will be viewed as favourable or unfavourable from the perspective of family, friends, colleagues; and community members using a 5-point Likert-type scale ranging from 1 (very unlikely) to 5 (very likely).

Seven items were adopted from [14] to measure the respondent's perception of threat and hazards posed by flood disaster. The construct was quantified using a 5-point Likert scale ranging from 1 (strongly disagree) to 5 (strongly agree).

Trust in agencies assessed trust level among respondents toward government agencies, to provide information in the event of flood and the perception of how civic agencies will act in the publics' best interest as well as policies to protect the general public. The instrument to measure trust in agencies was adopted from [14]. The construct consisted of five items where respondents were asked to rate the items using a 5-point Likert scale ranging from 1 (strongly disagree) to 5 (strongly agree).

The construct of sense of community adopted from [14]. that assessed place of attachment, participation and community involvement in the complex social network. The scale consisted 
of nine items where respondents were to rate the question using a 5-point Likert scale ranging from 1 (strongly disagree) to 5 (strongly agree).

Respondent's intention to prepare for flood adopted from [16]. The questions asked were to investigate whether respondents have intention to take preparatory actions. The items reflect actions to identify flood prepared level, make flood evacuation plan, community participation to reduce flood damages and to seek information on flood disaster. Total of 4 items were included in the measurement quantified using a 5-point Likert scale ranging from 1 (strongly disagree) to 5 (strongly agree). The cronbach's alpha values are acceptable as value of the scales ranges from 0.5 to 0.9 .

\section{Data Collection and Analysis}

Interview survey mode of data collection was used for respondents who were unable to read properly and selfadministered was adopted for educated respondents. A token of appreciation was given to all the respondents upon completion of the questionnaires.

SPSS was used for statistical analysis which comprise of descriptive statistics, bivariate analysis and multiple regression to determine the most influential factor for intention to prepare and preparedness to flood disaster.

\section{FINDINGS AND DISCUSSION}

Slightly more than half of the respondents were male (58\%). On average the respondents are aged 50 years old and half of the respondents were of Malay (59\%) ethnicity followed by Chinese (34\%) and Indian (7\%). The average household income was RM 2,322 well below the median (RM4, 163) household income for Sarawak state population and in the bottom 40 percent (RM 3,000) of Malaysian population (DOS, 2016). Education wise, $60 \%$ had attended secondary school (for 12-17 years old children) and an average of six household members. Most of the information received on flood is through television (72\%) followed by radio (61\%) and friends (55\%).

Table I shows the mean values of all the variables of the study except preparedness to flood disaster.

TABLE I: MEAN VALUE OF VARIABLES

\begin{tabular}{|l|l|l|}
\hline Variable & No of items & Mean \\
\hline Critical awareness & 2 & 3.92 \\
\hline Attitude towards flood & 8 & 3.10 \\
\hline Subjective norm & 6 & 3.39 \\
\hline Risk perception & 8 & 3.59 \\
\hline Trust in agencies & 5 & 3.74 \\
\hline Sense of community & 9 & 4.00 \\
\hline Intention to prepare & 4 & 3.79 \\
\hline
\end{tabular}

Scale: 1 (strongly disagree) to 5 (strongly agree)

It can be observed from the table above that the mean score for all the variables except for sense of community is above 3 but below 4 . It can be concluded that they are at moderate level.

For flood preparedness, there were 23 items with a scale of yes (1) or no (0) and hence the maximum score is 23 . The average score for the preparedness was 14.7 which show moderate level of preparedness. By dividing the score into three groups, namely low (1-13), moderate (14-17) and high (17-24), a total of $38 \%, 23 \%$ and $40 \%$ of the respondents were low, moderate and high level of preparedness consecutively. Among the items which were least prepared were related to property insurance. For subjective norm, family members were influential social agents for taking flood preparedness protective measures as compared to friends, colleagues or neighbours.

Multiple regression analysis revealed that none of the variable was predictors of preparedness. But intention to prepare correlate significantly with preparedness. However risk perception, trust in agencies and sense of community explained 57.3 percent of the variance in intention to prepare and the strongest predictor was trust in agencies.

\section{CONCLUSION}

It has been shown that vulnerable people to flooding are those in the low income group [17]. The data in the study shows that the average income of the respondents was way below a national average of RM6958 (year 2016). This is reflective in the inability of the respondents to insure their transport and properties against disasters. Similar findings were found among tsunami disaster risk population in Penang, Malaysia [10]. Suitable government policies or collaboration with financial institutions could be formulated to offer subsidized insurance coverage for the low income households. This will relieve total dependence on the government for rebuilding lives after a disaster. As in [18], the Government spend substantial sum of money for flood relief aid to the victims in addition to rebuilding damaged infrastructures.

With a high sense of community amongst the respondents, community based activities and programs could be organized with the local response agencies and local government in order to increase rapport and higher trust in agencies. Educational and campaigns for disaster preparedness ought to involve family members as they supported and motivate each other for preparedness. One of the strategies for disaster risk reduction identified by United Nations International Strategy Disaster Reduction (UNISDR) is to enhance community preparedness through community based disaster risk management (CBDRM) with the core fundamental of developing a resilient community against disasters [19], (Shaw, 2012) is therefore viable for the community under study.

\section{ACKNOWLEDGMENT}

We are deeply grateful to research officers from Humanitarian Assistance and Disaster Relief (HADR) Research Centre of National Defence University of Malaysia, Ms. Noor Diyana Fazan Ahmad and Mr. Mohd Muhaimin Ridwan Wong as well as our research assistant Ms. Syakura A Rahim for their contributions in this study. We would also like to acknowledge with appreciation all individuals and organizations who have contributed directly or indirectly to the successful completion of this project. 


\section{REFERENCES}

[1] Paridah, A. (2015). Malaysian Capacity Development Network for Sustainable Water Management: Annual Report for 2015. Kuala Lumpur, Malaysia: Malaysian Capacity Development Network for Sustainable Water Management.

[2] Jamal Hisham, H. (2015. Malaysian 2014 flood: Health impacts and experiences. Paper presented at Symposium on Flooding and Health Risk Reduction, Kuala Lumpur, 26 October 2015.

[3] Kamarulazizi, I., Kanayathu, C. K., Noor Adelyna, M. A., Radieah, M. N., Normaliza, A. M., \& Sharifah, Nurlaili Farhana Syed Azhar, et al. (Eds.). 2015. Kelantan Flood Disaster Management Conference 2015. Pulau Pinang, Malaysia: Centre for Global Sustainability Studies.

[4] Aini, M. S., Fakhru'l-Razi, A., Elistina, A. B., \& Norhasmah, S. (2016). Emergency Shelter Experiences and Preparedness among 2014 Flood Victims in Kelantan, Malaysia. In International Disaster and Risk Conference IDRC. Davos, Switzerland.

[5] Ercan, A., Fauzi, M. M., \& Kavvas, M. L. (2013). The impact of climate change on sea level rise at Peninsular Malaysia and Sabah-Sarawak. Hydrological Processes, 27(3), 367-377. https://doi.org/10.1002/hyp.9232

[6] Lindell, M. K. (2013). Disaster studies. Current Sociology, 61(5-6), 797-82. https://doi.org/10.1177/0011392113484456

[7] Aini, M. S., Fakhru'l-Razi, A., Ahmad Rodzi, M., \& Fuad, A. (2011). Community preparedness for tsunami disaster: A case study. Disaster Prevention and Management, 20(3), 266-280. https://doi.org/10.1108/09653561111141718

[8] Becker, J., McBride, S., \& Paton, D. (2013). Improving community resilience in the Hawke's Bay: A review of resilience, and current public education, communication and resilience strategies. GNS Science Report, 2012/38, 1-82

[9] Lindell, M. K., Prater, C. S., Gregg, C. E., Apatu, E. J.I., Huang, S.-K., \& $\mathrm{Wu}, \mathrm{H}$. C. (2015). Households' immediate Responses to the 2009 American Samoa Earthquake and Flood. International Journal of Disaster Risk Reduction, 12, 328-340. https://doi.org/10.1016/j.ijdrr.2015.03.003

[10] Syakura, A.R. (2014). Intention to prepare for tsunami disaster among households in Penang. Master Thesis: Universiti Putra Malaysia.

[11] Terpstra, T. (2011). Emotions, trust, and perceived risk: affective and cognitive routes to flood preparedness behavior. Risk Analysis, 31(10), 1658-1675. https://doi.org/10.1111/j.1539-6924.2011.01616.x

[12] Paton, D., Kelly, G., Burgelt, P. T., \& Doherty, M. (2006a). Preparing for bushfires: understanding intentions. Disaster Prevention and Management, 15(4), 566-575. https://doi.org/10.1108/09653560610685893

[13] Sivan Kohn, Jennifer Lipkowitz Eaton, Saad Feroz, Andrea A. Bainbridge, Jordan Hoolachan and Daniel J. Barnett (2012). Personal Disaster Preparedness: An Integrative Review of the Literature. Disaster Medicine and Public Health Preparedness, 6(3), 217-231. https://doi.org/10.1001/dmp.2012.47

[14] Frandsen, M. (2012). Promoting community bushfire preparedness: Bridging the theory - Practice Divide. Doctor of Philosophy (Psychology), Tasmania, Australia.

[15] McIvor, D., \& Paton, D. (2007). Preparing for natural hazards: Normative and attitudinal influences. Disaster Prevention and Management, 16(1), 79-88. https://doi.org/10.1108/09653560710729839

[16] Paton, D., Smith, L., \& Johnston, D. (2005). When good intentions turn bad: Promoting natural hazard preparedness. The Australian Journal of Emergency Management, 20(1), 25-30.

[17] Chan, N. W. (2012). Impacts of Disasters and Disasters Risk Management in Malaysia: The Case of Floods. In Y. Sawada \& S. Oum (Eds.), Economic and Welfare Impacts of Disasters in East Asia and Policy Responses. (pp. 503-551). Jakarta, Indonesia: ERIA.

[18] Aini, M.S., Fakhru'l-Razi, A. \& Ahmad Azan, R. (2018). Flood disaster management and preparedness among communities and responding agencies in Malaysia. A report submitted to National Humanitarian Assistance \& Disaster Relief Centre, National Defense University of Malaysia.

[19] Shaw, R. (Ed.) (2014). Disaster Risk Reduction: Method, Approaches and Practices. Recovery from the Indian Ocean Flood: A Ten-Year Journey. Japan: Springer. https://doi.org/10.1007/978-4-431-54246-9_1

[20] G. O. Young, "Synthetic structure of industrial plastics (Book style with paper title and editor)," in Plastics, 2nd ed. vol. 3, J. Peters, Ed. New York: McGraw-Hill, 1964, pp. 15-64.

Thank you to Janus TDC Ltd (UK) for funding this project. 